Syntax Literate : Jurnal Ilmiah Indonesia p-ISSN: 2541-0849

e-ISSN : 2548-1398

Vol. 5, No. 2 Februari 2020

\title{
MODEL ALAT UKUR DEBIT UNTUK SALURAN IRIGASI
}

\author{
Akbar Winasis, Heri Mulyono dan Nurdiyanto \\ Fakultas Teknik Universitas Swadaya Gunung Jati (UGJ) Cirebon \\ Email: barswinz@yahoo.co.id, mulyonoh29@gmail.com dan nurdiantomj1@gmail.com
}

\section{Abstract}

One of the existing infrastructure in the irrigation network system is a debit measurement tool. This discharge measurement tool is a water structure that regulates the flow of water into irrigation channels or directly into rice fields. The need for water in paddy fields depends on cropping patterns so that it needs optimal water regulation so that it is right on target, fair to all water users in the fields and not wasteful in water use. This research specifically aims to regulate the provision of irrigation water in irrigation channels by creating a model for measuring discharge. From the results of the field survey, a debit measurement tool was made. The stages of the research method are divided into three stages, namely data collection, data processing and output in the form of a discharge table $(Q)$ of water level $(H)$. The data is taken from the results of the measuring instrument experiments with three models, namely the first model with a slope of 1: 0.25, the second model with a ratio of 1: 0.5 and the third model 1: 0.75. Water is flowed through the three models with varying expenditure discharges. The results of the study showed that for the first variation of discharge testing that in the first model the magnitude of $H$ was $0.015 \mathrm{~m}$ and $Q$ was $0.000342 \mathrm{~m} 3 / \mathrm{s}$. For the second model the magnitude of $H$ is $0.013 \mathrm{~m}$ and $Q$ is $0.000276 \mathrm{~m} 3 / \mathrm{s}$. For the third model the magnitude of $H$ is $0.015 \mathrm{~m}$ and $Q$ is $0.000342 \mathrm{m3} / \mathrm{s}$.

Keywords: Irrigation Channels, Model Measuring Instruments, Discharge, Water Levels

\begin{abstract}
Abstrak
Salah satu infrastruktur yang ada pada sistem jaringan irigasi adalah alat ukur debit. Alat ukur debit ini adalah bangunan air yang mengatur debit air ke saluran irigasi atau langsung ke petak sawah. Kebutuhan air di petak sawah tergantung pada pola tanam sehingga perlu pengaturan air yang optimal supaya tepat sasaran, adil untuk semua pengguna air di sawah dan tidak boros dalam penggunaan air. Penelitian ini secara khusus bertujuan untuk mengatur pemberian air irigasi di saluran irigasi dengan membuat model alat ukur debit. Dari hasil survey lapangan, maka dibuat model alat ukur debit. Tahapan metode penelitian terbagi dalam tiga tahapan, yaitu pengumpulan data, pengolahan data dan keluaran berupa tabel debit (Q) terhadap tinggi muka air $(\mathrm{H})$. Data diambil dari hasil percobaan alat ukur dengan tiga model yaitu model pertama dengan kemiringan 1:0,25, model kedua dengan perbandingan 1:0,5 dan model ketiga 1:0,75. Air dialirkan melalui ketiga model tersebut dengan debit pengeluaran yang bervariasi. Hasil dari penelitian menunjukkan untuk debit variasi pengujian pertama bahwa pada model pertama besarnya $\mathrm{H}$ adalah $0,015 \mathrm{~m}$
\end{abstract}


dan Q adalah $0,000342 \mathrm{~m}^{3} / \mathrm{s}$. Untuk model kedua besarnya $\mathrm{H}$ adalah $0,013 \mathrm{~m}$ dan $\mathrm{Q}$ adalah $0,000276 \mathrm{~m}^{3} / \mathrm{s}$. Untuk model ketiga besarnya $\mathrm{H}$ adalah $0,015 \mathrm{~m}$ dan $\mathrm{Q}$ adalah $0,000342 \mathrm{~m}^{3} / \mathrm{s}$.

Kata kunci : Saluran Irigasi, Model Alat Ukur, Debit, Tinggi Muka Air

\section{Pendahuluan}

Debit Air dapat didefinisikan sebagai suatu koefisien yang menyebutkan banyaknya air yang mengalir dari sumber air per satuan waktu (Permatasari, Sabar, \& Natakusumah, 2017) biasanya diukur dalam satuan $\mathrm{m}^{3} /$ detik. Pengukuran debit dapat dilakukan dengan berbagai cara, antara lain: pengukuran debit dengan bendung, pengukuran debit berdasarkan kerapatan, pengukuran kecepatan aliran dan luas penampang melintang, dalam hal ini untuk mengukur kecepatan arus digunakan pelampung atau pengukur arus, pengukuran dengan menggunakan alat tertentu seperti pengukur arus magnetis, pengukur arus gelombang supersonik (Sumirman \& Lasminto, 2013). Perkembangan teknologi tersebut menyebabkan banyak perubahan dalam pemakaian sistem peralatan diseluruh bidang termasuk pengukuran listrik (Supriatna, 2019).

Untuk memenuhi kebutuhan air irigasi, debit air di daerah bendung harus lebih cukup untuk disalurkan ke saluran-saluran (induk-sekunder-tersier). Supaya penyaluran air ke suatu areal dapat diatur dengan sebaik- baiknya (dalam arti tidak berlebihan atau agar dapat dimanfaatkan seefisien mungkin, dengan mengingat kepentingan areal lahan lainnya) maka dalam pelaksanaanya perlu dilakukan pengukuran debit air. Dengan distribusi yang terkendali, dengan bantuan pengukuran-pengukuran tersebut, maka masalah kebutuhan air irigasi selalu dapat diatasi tanpa menimbulkan gejolak dimasyarakat petani pemakai air.

\section{Metode Penelitian}

Data yang dipergunakan dalam penelitian ini adalah data primer dan sekunder, dimana data primer yang dipergunakan adalah data saluran dan data debit. Sedangkan data sekunder yang dipergunakan dalam penelitian ini adalah berbagai sumber teoritik dan empirik yang berkaitan dengan perencanaan dan pembuatan model. Untuk membuat model alat ukur debit, terlebih dahulu dibuat rencana desain model alat ukur Cipoletti. Sebagai pembanding (Sahid, 2010). dilakukan survey lokasi lapangan ke saluran irigasi yang berfungsi dengan baik. Lokasi yang dijadikan sebagai referensi model alat ukur dipilih lokasi Daerah Irigasi Cipaniis Kabupaten Kuningan Jawa Barat.

Model saluran terbuka pemodelan fisik untuk mempelajari debit keluaran yang terjadi pada alat ukur debit dengan saluran lurus 180 derajat yang dilakukan di laboratorium Uji Model Hidraulika, Fakultas Teknik, Universitas Swadaya Gunung Jati. Saluran terbuka ini di modelkan dengan dinding dan dasar salurannya terbuat dari acrylic dan kaca. 


\section{Hasil dan Pembahasan}

\section{Survey Lapangan}

Untuk membuat model alat ukur debit, terlebih dahulu dilakukan survey lapangan sebagai pembanding. Survey lokasi lapangan dilakukan ke saluran irigasi yang berfungsi dengan baik. Lokasi yang dijadikan sebagai referensi model alat ukur dipilih lokasi Daerah Irigasi Cipaniis Kabupaten Kuningan Jawa Barat. Jarak dari tempat penelitian uji laboratorium ke tempat lokasi survey adalah kurang lebih 30 $\mathrm{km}$.

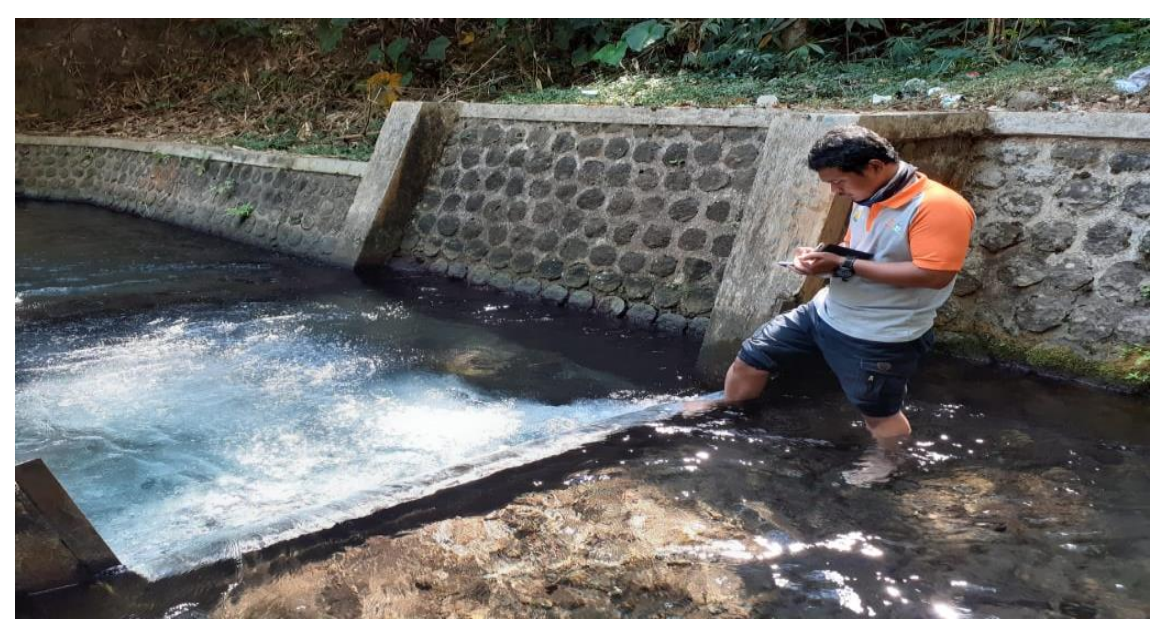

Gambar 1 Lokasi Survey Saluran Irigasi

\section{Desain Model}

Gambar desain model dibuat dengan bantuan program Auto CAD dengan tiga macam tipe bentuk, seperti pada gambar berikut

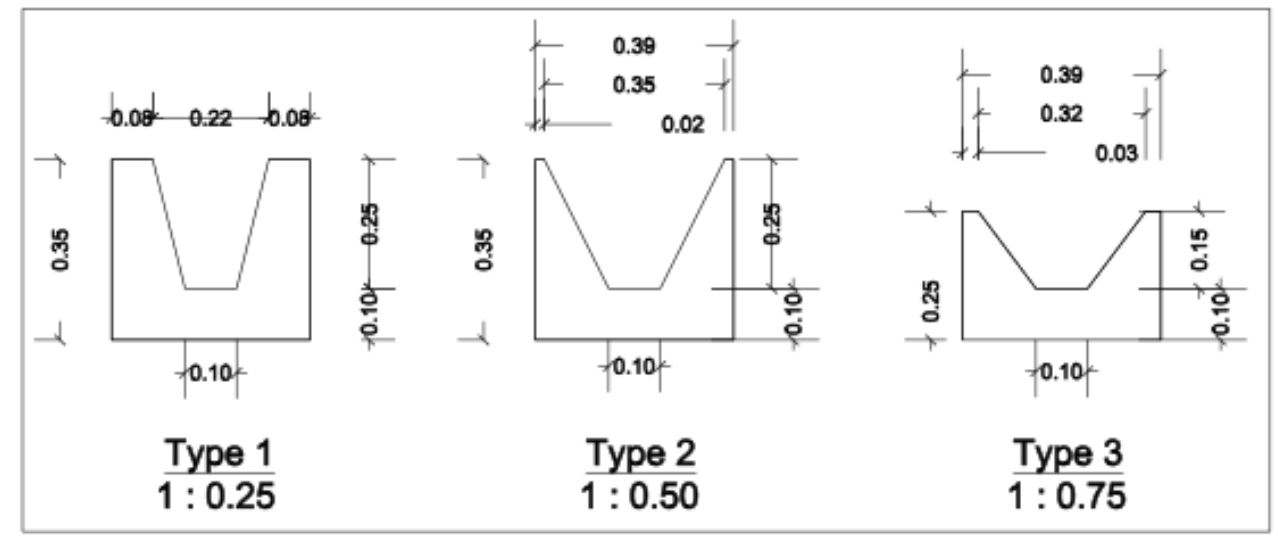

Gambar 2 Desain Model

\section{Pembuatan Model}

Bahan pembuatan model terbuat dari acrilik, dengan tiga macam model, seperti pada gambar di bawah ini 


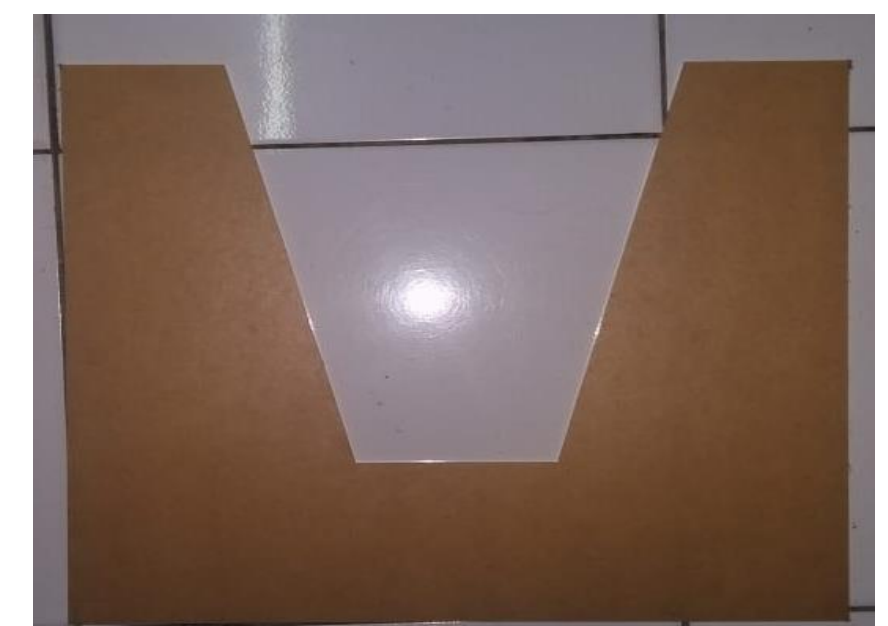

Gambar 3 Model 1

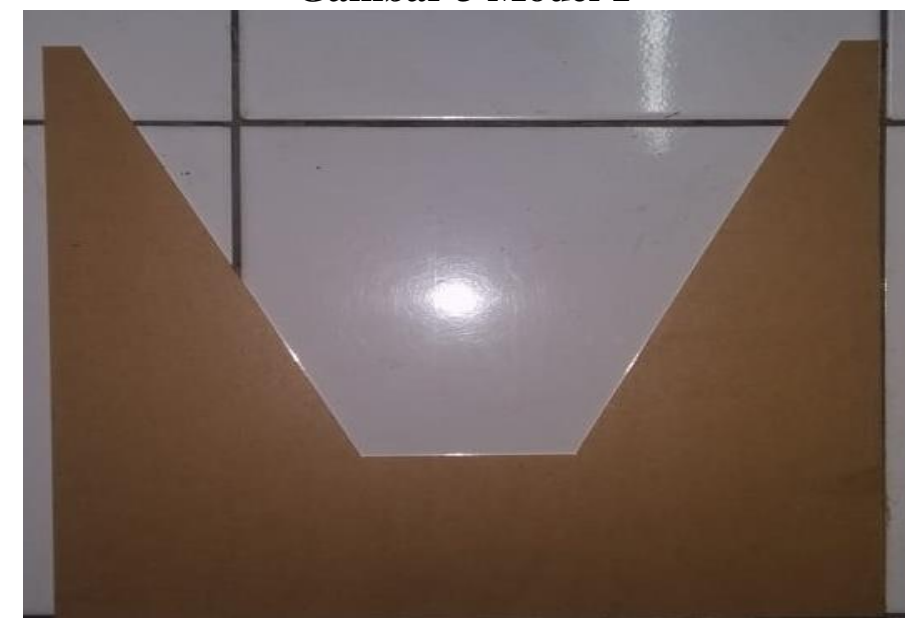

Gambar 4 Model 2

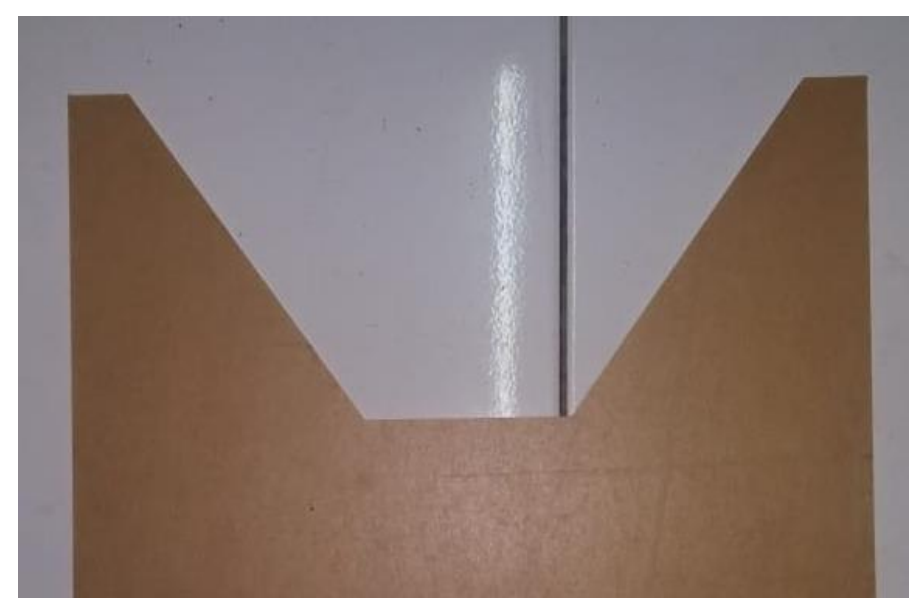

\section{Gambar 5 Model 3}

\section{Hasil Pengujian dan Analisis}

Sebelum dilakukan pengujian, terlebih dahulu model yang sudah di desain dipasang pada saluran flume (Nurrochmad, 2005) dengan masing-masing pengujian model, yaitu: 
a. Pasanglah model 1 pada flume saluran terbuka yang akan diukur debit airnya.

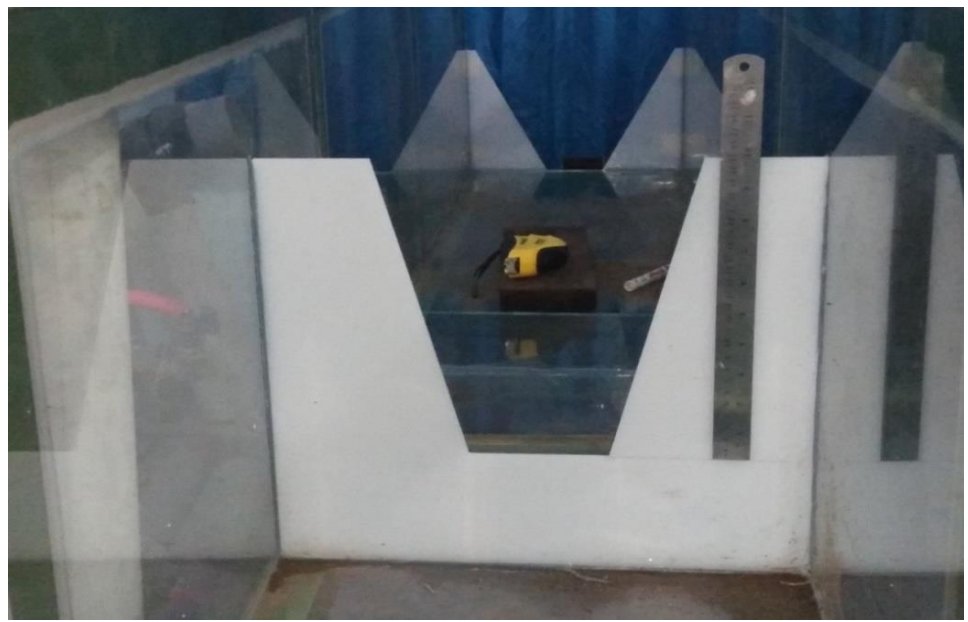

Gambar 6 Pemasangan Model pada Flume

b. Ukur posisi keseimbangan model pada flume dengan menggunakan waterpass

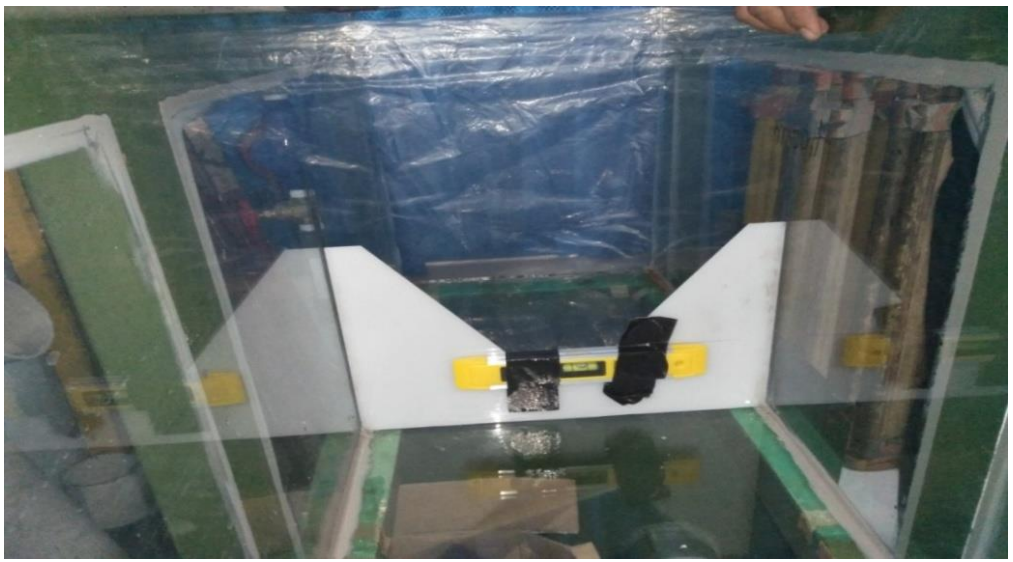

Gambar 7 Keseimbangan Model pada Flume

c. Atur pengeluaran debit dari pompa dengan memutarkan stop kran dengan putaran $5,4,5,4,3,5,3,1$.

d. Hitung kecepatan aliran dengan menggunakan formula manning Rizali, Nurhakim, Santoso, \& Novianti, 2019) yaitu

$$
V=\frac{1}{\mathrm{n}} \cdot \mathrm{R}^{2 / 3} \cdot I^{1 / 2}
$$

dimana:

$\mathrm{V}=$ kecepatan aliran $(\mathrm{m} / \mathrm{s})$

$\mathrm{n}=$ koefisien manning

$\mathrm{R}=$ jari-jari hidrolis

I = kemiringan dasar saluran 
e. Ukur tinggi muka air di atas model dan tentukan debit airnya.

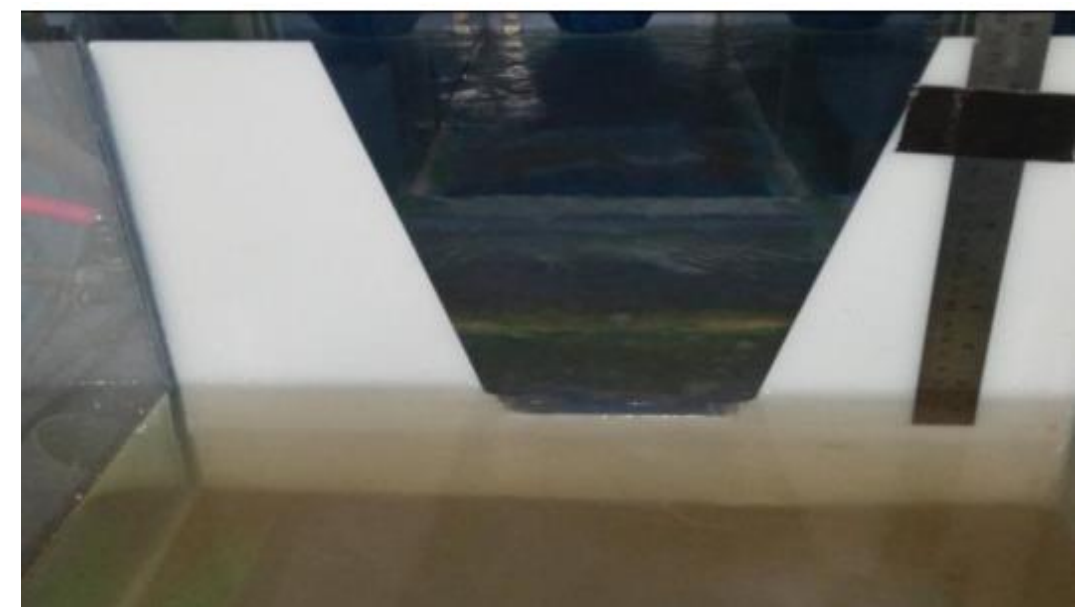

Gambar 8 Pengukuran Tinggi Muka Air pada Model

f. Lakukan langkah a sampai e di atas untuk model 2 dan model 3 (Rizali et al., 2019)

g. Dari hasil pengujian di atas untuk model alat 1 dengan debit yang bervariasi, didapat hasil seperti pada tabel berikut

Tabel 1 Hasil Analisis Model 1

\begin{tabular}{ccc}
\hline No. Pengujian & $\mathbf{h}(\mathbf{m})$ & $\mathbf{Q}\left(\mathbf{m}^{\mathbf{3}} \mathbf{s}\right)$ \\
\hline 1 & 0,015 & 0,000342 \\
\hline 2 & 0,018 & 0,000449 \\
\hline 3 & 0,035 & 0,001218 \\
\hline 4 & 0,042 & 0,001601 \\
\hline 5 & 0,045 & 0,001776 \\
\hline 6 & 0,046 & 0,001835 \\
\hline
\end{tabular}

Dari tabel di atas dapat dijelaskan bahwa ketika putaran kran 5, maka besarnya tinggi muka air di atas model alat adalah 0,015 m. Berdasarkan SNI 036455.5-2000 besarnya debit air dapat dihitung dengan formula sebagai berikut

$$
Q=1,86 \cdot \mathrm{b} \cdot \mathrm{h}^{3 / 2}
$$

dimana :

$$
\begin{array}{ll}
\mathrm{Q} & =\text { Debit }\left(\mathrm{m}^{3} / \mathrm{s}\right) \\
\mathrm{b} & =\text { Lebar ambang }(\mathrm{m}) \\
\mathrm{h} & =\text { Tinggi muka air }(\mathrm{m})
\end{array}
$$

maka besarnya debit air pada model alat 1 dengan putaran kran 5 dan tinggi muka air $0,015 \mathrm{~m}$ adalah

$$
\begin{aligned}
Q & =1,86 \cdot \mathrm{b} \cdot \mathrm{h}^{\frac{3}{2}} \\
& =1,86 \times 0,10 \times 0,015^{3 / 2} \\
& =0,000342 \mathrm{~m}^{3} / \mathrm{s}
\end{aligned}
$$




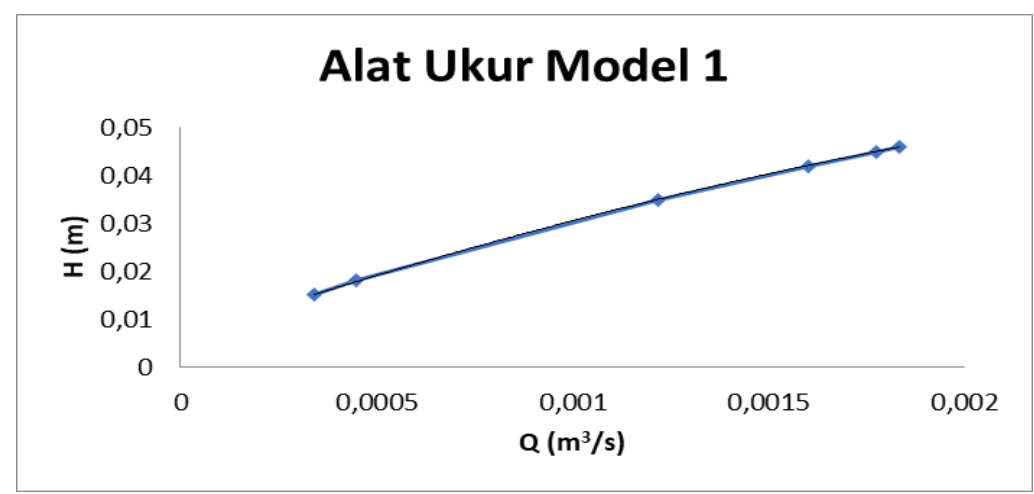

Gambar 9 Grafik Hubungan H dan Q Model 1

Dari grafik di atas kita dapat menentukan besarnya tinggi muka air atau besarnya debit, dengan menggunakan persamaan

$$
Q=0,397 h^{2}+0,024 h-0,0001
$$

h. Untuk model alat 2, dengan debit yang bervariasi, didapat hasil seperti pada tabel berikut:

Tabel 2 Hasil Analisis Model 2

\begin{tabular}{ccc}
\hline Putaran Kran & h (m) & $\mathbf{Q}\left(\mathbf{m}^{\mathbf{3}} / \mathbf{s}\right)$ \\
\hline 1 & 0,013 & 0,000276 \\
\hline 2 & 0,033 & 0,001115 \\
\hline 3 & 0,040 & 0,001488 \\
\hline 4 & 0,042 & 0,001601 \\
\hline 5 & 0,043 & 0,001659 \\
\hline 6 & 0,045 & 0,001776 \\
\hline
\end{tabular}

Dari tabel di atas dapat dijelaskan bahwa ketika putaran kran 5, maka besarnya tinggi muka air di atas model alat adalah 0,013 m. Berdasarkan SNI 03-6455.52000 besarnya debit air dapat dihitung dengan formula sebagai berikut

$$
Q=1,86 \cdot \mathrm{b} \cdot \mathrm{h}^{3 / 2}
$$

dimana :

Q $\quad=$ Debit $\left(\mathrm{m}^{3} / \mathrm{s}\right)$

$\mathrm{b}=$ Lebar ambang $(\mathrm{m})$

$\mathrm{h}=$ Tinggi muka air $(\mathrm{m})$

maka besarnya debit air pada model alat 1 dengan putaran kran 5 dan tinggi muka air $0,013 \mathrm{~m}$ adalah

$$
\begin{aligned}
Q & =1,86 \cdot \mathrm{b} \cdot \mathrm{h}^{\frac{3}{2}} \\
& =1,86 \times 0,10 \times 0,013^{\wedge} \wedge^{3 / 2} \\
& =0,000276 \mathrm{~m}^{3} / \mathrm{s}
\end{aligned}
$$




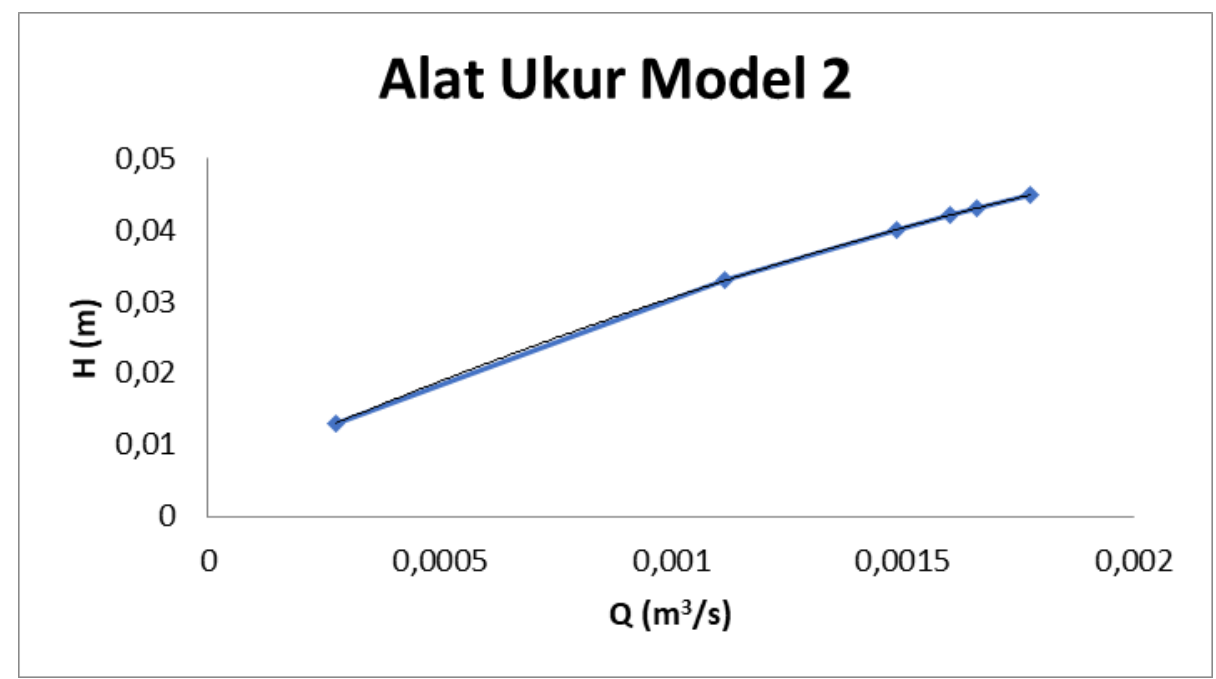

Gambar 10 Grafik Hubungan H dan Q Model 2

Dari grafik di atas kita dapat menentukan besarnya tinggi muka air atau besarnya debit, dengan menggunakan persamaan

$$
Q=0,407 h^{2}+0,023 h-0,0001
$$

i. Untuk model alat 3, dengan debit yang bervariasi, didapat hasil seperti pada tabel berikut

Tabel 3 Hasil Analisis Model 3

\begin{tabular}{ccc}
\hline Putaran Kran & h (m) & $\mathbf{Q}\left(\mathbf{m}^{\mathbf{3}} / \mathbf{s}\right)$ \\
\hline 1 & 0,015 & 0,000342 \\
\hline 2 & 0,033 & 0,001115 \\
\hline 3 & 0,041 & 0,001544 \\
\hline 4 & 0,043 & 0,001659 \\
\hline 5 & 0,045 & 0,001776 \\
\hline 6 & 0,047 & 0,001895 \\
\hline
\end{tabular}

Dari tabel di atas dapat dijelaskan bahwa ketika putaran kran 5, maka besarnya tinggi muka air di atas model alat adalah 0,015 m. Berdasarkan SNI 03-6455.52000 besarnya debit air dapat dihitung dengan formula sebagai berikut

$$
Q=1,86 \cdot \mathrm{b} \cdot \mathrm{h}^{3 / 2}
$$

dimana :

Q $\quad=\operatorname{Debit}\left(\mathrm{m}^{3} / \mathrm{s}\right)$

$\mathrm{b}=$ Lebar ambang $(\mathrm{m})$

$\mathrm{h}=$ Tinggi muka air $(\mathrm{m})$

maka besarnya debit air pada model alat 1 dengan putaran kran 5 dan tinggi muka air $0,015 \mathrm{~m}$ adalah 


$$
\begin{aligned}
Q & =1,86 \cdot \mathrm{b} \cdot \mathrm{h}^{\frac{3}{2}} \\
& =1,86 \times 0,10 \times 0,015^{\wedge^{3 / 2}} \\
& =0,000342 \mathrm{~m}^{3} / \mathrm{s}
\end{aligned}
$$

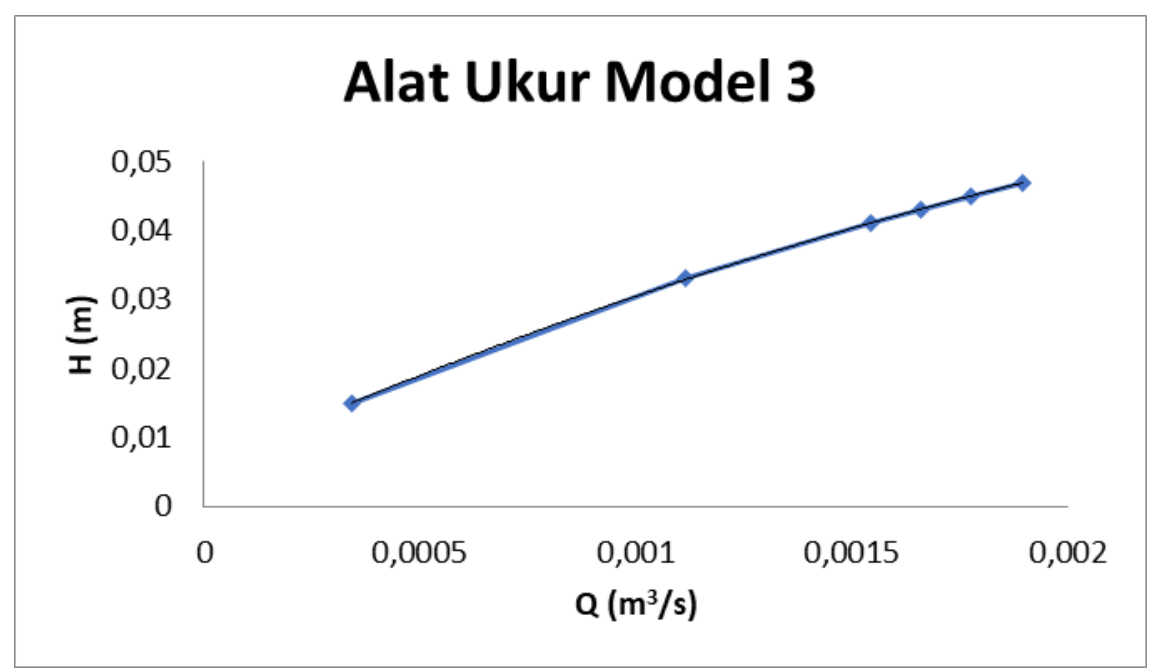

Gamba 11 Grafik Hubungan H dan Q Model 3

Dari grafik di atas kita dapat menentukan besarnya tinggi muka air atau besarnya debit, dengan menggunakan persamaan

$$
\mathrm{Q}=0,396 \mathrm{~h}^{2}+0,024 \mathrm{~h}-0,0001
$$

\section{Kesimpulan}

Dari hasil pembahasan di atas mengenai model alat ukur debit, maka dapat diambil kesimpulan sebagai berikut:

1. Model alat ukur debit dibuat dengan 3 model alat yang berbeda, dipasang pada flume saluran terbuka

2. Model alat ukur mempunyai ukuran dengan lebar ambang $0,10 \mathrm{~m}$

3. Hasil dari penelitian menunjukkan bahwa dengan debit variasi untuk pengujian pertama, pada model pertama besarnya $\mathrm{H}$ adalah $0,015 \mathrm{~m}$ dan $\mathrm{Q}$ adalah 0,000342 $\mathrm{m}^{3} / \mathrm{s}$. Untuk model kedua besarnya $\mathrm{H}$ adalah $0,013 \mathrm{~m}$ dan $\mathrm{Q}$ adalah $0,000276 \mathrm{~m}^{3} / \mathrm{s}$. Untuk model ketiga besarnya $\mathrm{H}$ adalah $0,015 \mathrm{~m}$ dan Q adalah $0,000342 \mathrm{~m}^{3} / \mathrm{s}$

4. Persamaan yang dapat digunakan untuk mencari nilai $Q$ pada model alat 1 adalah

$$
\mathrm{Q}=0,397 \mathrm{~h}^{2}+0,024 \mathrm{~h}-0,0001
$$

5. Persamaan yang dapat digunakan untuk mencari nilai $Q$ pada model alat 2 adalah

$$
\mathrm{Q}=0,407 \mathrm{~h}^{2}+0,023 \mathrm{~h}-0,0001
$$

6. Persamaan yang dapat digunakan untuk mencari nilai $Q$ pada model alat 3 adalah

$$
Q=0,396 h^{2}+0,024 h-0,0001
$$




\section{BIBLIOGRAFI}

Nurrochmad, F. (2005). Analisis Kalibrasi Bangunan Ukur Debit Cipoletti. Media Teknik, 27(2005).

Permatasari, R., Sabar, A., \& Natakusumah, D. K. (2017). Pengaruh Perubahan Penggunaan Lahan terhadap Rezim Hidrologi DAS (Studi Kasus: DAS Komering). Journal of Civil Engineering, 24(1), 91-98.

Rizali, R., Nurhakim, N., Santoso, E., \& Novianti, Y. S. (2019). Evaluasi Volume Tampung Dari SUMP Dengan Persamaan Water Balance. Jurnal Himasapta, $1(01)$.

Sahid, N. (2010). Eksistensi Kritik Teater Di Media Cetak: Sebuah Tinjauan Kritis. Dewa Ruci: Jurnal Pengkajian Dan Penciptaan Seni, 6(2).

Sumirman, E., \& Lasminto, U. (2013). Studi Perbandingan Aliran Alat Ukur Debit Ambang Tipis Penampang Segi Tiga dengan Penampang Majemuk. Prosiding Seminar Nasional Aplikasi Teknologi Prasarana Wilayah (ATPW), 1-18.

Supriatna, A. (2019). Penerapan Model Pembelajaran Kooperatif Tipe Group Investigation Untuk Meningkatkan Hasil Belajar Dasar dan Pengukuran Listrik Siswa Kelas X Titl-1 SMK Negeri 3 Kuningan. Syntax Literate; Jurnal Ilmiah Indonesia, 4(12), 36-46. 